\title{
Stinging wasps (Hymenoptera: Aculeata), which species have the longest sting?
}

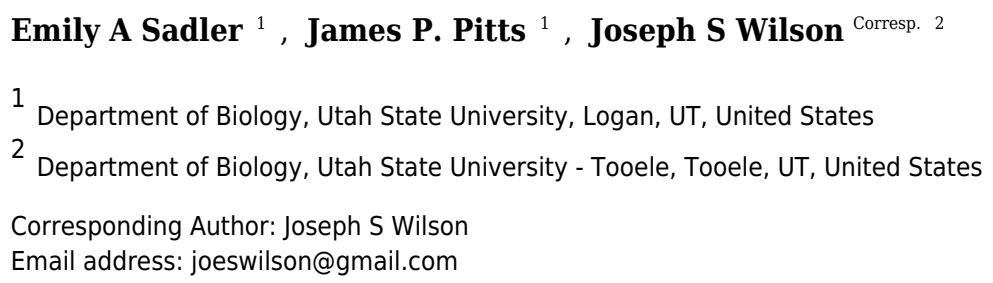

The stings of bees, wasps, and ants are something that catches the attention of anyone that experiences them. While many recent studies have focused on the pain inflicted by the stings of various stinging wasps, bees, or ants (Hymenoptera: Aculeata), little is known about how the length of the sting itself varies between species. Here, we investigate the sting length of a variety of aculeate wasps, and compare that to reported pain and toxicity values. We find that velvet ants (Hymenoptera: Mutillidae) have the longest sting compared to their body size out of any bee, wasp, or ant species. We also find that there is no link between relative sting length and pain; however, we did find an inverse relationship between relative sting length and toxicity with taxa having shorter relative stings being more toxic. While we found a significant relationship between host use and relative sting length, we suggest that the long sting length of the velvet ants is also related to their suite of defenses to avoid predation. 
1 Stinging wasps (Hymenoptera: Aculeata), which species have the longest sting?

2

3 Emily A. Sadler ${ }^{1}$, James P. Pitts ${ }^{1}$, \& Joseph S. Wilson ${ }^{2}$

4

5 'Department of Biology, Utah State University, 5305 Old Main Hill, Logan, UT 84322, USA.

$6{ }^{2}$ Department of Biology, Utah State University Tooele, 1021 West Vine Street, Tooele, UT

$7 \quad 84074$

8 Corresponding author:

9 Joseph Wilson

10 Email address: Joeswilson@gmail.com 


\section{Abstract}

13 The stings of bees, wasps, and ants are something that catches the attention of anyone that experiences them. While many recent studies have focused on the pain inflicted by the stings of various stinging wasps, bees, or ants (Hymenoptera: Aculeata), little is known about how the length of the sting itself varies between species. Here, we investigate the sting length of a variety

17 of aculeate wasps, and compare that to reported pain and toxicity values. We find that velvet ants

18 (Hymenoptera: Mutillidae) have the longest sting compared to their body size out of any bee,

19 wasp, or ant species. We also find that there is no link between relative sting length and pain;

20 however, we did find an inverse relationship between relative sting length and toxicity with taxa

21 having shorter relative stings being more toxic. While we found a significant relationship

22 between host use and relative sting length, we suggest that the long sting length of the velvet ants

23 is also related to their suite of defenses to avoid predation. 


\section{Introduction}

27

Hymenoptera (ants, bees, and wasps) have likely been of interest to humans for as long as we have existed. Our histories are tied closely together with Hymenoptera. Paleolithic paintings depicting bees have been found dating from 15,000 years ago in the caves of Spain, and pottery vessels used for beekeeping have been found dating from 9,000 years ago (Piek 1986; RoffetSalque et al. 2015). However, as we have sought out honey and wax for our own benefit during the Meso- and Neolithic, we also were undoubtedly introduced to bee's defensive stings. While colloquially many refer to the "stinger" of bees, wasps, and ants, among entomologists the correct term both for the stinging structure (the noun) and the action (the verb) is simply "sting" and as entomologists we will refer to the structure as such. For example, it would be correct to say "the bee was able to sting me with her sting" rather than "...sting me with her stinger." Bees, ants, and many of the more familiar wasps fall within an infraorder of Hymenoptera called Aculeata, which is defined by the modification of the egg laying device (ovipositor) into a sting apparatus. Among the aculeates, the use of the sting is primarily for prey capture or host paralysis, and defense. While people often associated stings with bees, many wasps, and ants have even more painful stings than bees (Schmidt 2016).

Hymenoptera venom is the most potent of any of the animal venom (Schmidt 1990a). An estimated 100 deaths per year can be attributed to stinging Hymenoptera, which is 3-4 times the number of deaths that occur by snake bites (Schmidt 1986a). However, with the exception of allergic reactions, most people only experience temporary pain and edema. In fact, an adult human could safely withstand 1,000 bee stings (Fitzgerald \& Flood 2006). It is estimated that a 
47 lethal dose does not occur until a threshold of 20 stings/kg (Fitzgerald \& Flood 2006). Although

48 the result of a large number of stings may not be death, pain is a certainty.

As many of us have experienced, the amount of pain that bee and wasp stings cause

varies by species. Yet for some reason, a bee sting (generally the sting of a European honey bee, Apis mellifera) has become somewhat of a benchmark for pain. A shot at the doctor's office, for example, is often equated to a "quick sting, no worse than a bee." Starr (1985), with the later expansion by Schmidt (1990a) and Schmidt (2016), created a pain scale that opens the topic of sting pain up to a more general audience. This method ranks pain on a scale that varies from one, which is the least painful, and includes small sweat bees (Lasioglossum spp.) and native fire ants (Solenopsis geminata), to four, which is the most painful, and includes the bullet ant

(Paraponera clavata) and tarantula hawks (Pepsis spp.) (Schmidt 2016).

Pain from wasp envenomation can come from two sources with the first being from the chemical composition of venom itself. Hymenoptera venom can be two forms, alkaloid and proteinaceous (Blum 2012; Schmidt et al. 1986). Hymenoptera venoms are known to vary in toxicity as given by studies of $\mathrm{LD}_{50}$ (a measure of lethality) and enzymatic activity. Schmidt et al. (1980) found that the $\mathrm{LD}_{50}$ of various aculeate wasps varied from $0.25 \mathrm{mg} / \mathrm{kg}$ to $71 \mathrm{mg} / \mathrm{kg}$ with harvester ants (Pogonomyrmex spp.) having the most toxic venoms and velvet ants (Dasymutilla klugii) and the German hornet (Paravespula germanica) having the least toxic of the venoms. Schmidt et al. (1986) found that aculeate venom also varies in eight different enzymes with species of velvet ants (Dasymutilla lepeletierii) once again having some of the lowest of the enzymatic activities.

The second cause of pain is due to mechanical damage from the sting puncturing tissue. Spider wasps (Pompilidae) and velvet ants seem to be paradoxical having a high pain rating, but 
70 a low $\mathrm{LD}_{50}$ and weak enzymatic activity (Schmidt 1986a; Schmidt 2004; Schmidt et al. 1980).

71 Observations have been made that the wasps having the highest pain indices on the Schmidt and

72 Starr Pain Scale (Schmidt 1990a; Schmidt 2016; Starr 1985) are often those with the largest

73 bodies. The reason that these wasps cause intense pain may be due to the morphology of the

74 sting itself. Much attention has been paid to the chemical components of venom, but little has

75 been done concerning the morphology of the sting, and specifically its relative length. While

76 comparisons of ovipositor length have been done for parasitoid wasps (Townes 1975), no

77 comparisons have been made among the stinging wasps, the aculeates.

78 In this study we investigate the relative length of the stings of various aculeate wasps and 79 compare these lengths to known measures of toxicity, enzyme activity, and pain. A particular 80 focus is given to the velvet ants (Mutillidae), because they are known to not only have a painful 81 (yet relatively harmless) sting, but also, they are known to have an exceptionally long sting 82 (Schmidt 2016) (Fig. 1a).

\section{Methods}

85 Sting length

The stings were measured for species from 14 families of aculeates (including ants and bees) (Table 1). All specimens were sourced from the Department of Biology Insect Collection at Utah State University (EMUS). The sting from each specimen was dissected and photographed using a Leica camera and microscope with light dome; calibrations were checked prior to any photographs. Measurements were taken from the tip of the lancet along the curve of

91 the sting shaft to the beginning of the triangular plate using Image J (Rasband et al. 2011). In

92 order to obtain a relative measure of sting length to body size, the mesosomal length was 
93 measured as a proxy to overall body length. Because position of the head varies from specimen

94 to specimen, and the gaster can be expanded or contracted depending on the specimen, total body

95 lengths are difficult to determine and are not consistent from one individual to another. While

96 various proxies have been used to estimate body length of Hymenoptera, including head width

97 (Haggard \& Gamboa 1980), intertegular distance (Greenleaf et al. 2007), and wing length (Bosch

98 \& Vicens 2002), proxies associated with wings could not be used, as not all aculeates have wings

99 (i.e., ants and velvet ants). We selected the mesosoma as a proxy for body length, as it is not

100 moveable and can easily be measured in preserved specimens. For a consistent measurement the

101 mesosoma was measured form the anterior apex of the pronotal flange to the dorsal margin of the

102 propodeal foramen in lateral view. Multiple images of each specimen were taken using a Leica

103 camera with light dome. All images were then combined using Zerene Stacker v1.04, and

104 measurements were made (based on 1mm scale bar) using Image J (Rasband et al. 2011).

105 Measurements were made in replicate depending on if the species was common. For

106 common species, stings were extracted from five individuals and measurements of both the sting

107 and the mesosoma were made for each specimen. These are indicated in Table 1 by those

108 individuals with a standard deviation (STD) for both sting measurements and mesosomal length

109 measurements. Because sting dissection is a destructive process, only a single specimen was

110 extracted in instances where a species was rare. These species are indicated on Table 1 by those

111 individuals without STD for either sting measurements or mesosomal length measurements

112 We also wanted to make use of the extensive slide collection of aculeate stings at the

113 Department of Biology Insect Collection at Utah State University (EMUS). However, most

114 stings previously slide mounted had no associated voucher specimen, likely due to the

115 destructive nature of sting extraction. To make use of these slides and avoid the destruction of 
116 additional museum specimens, for those species where a slide-mounted sting was available we

117 selected five individuals of that same species from the EMUS collection and the mesosomal

118 lengths were measured for these specimens. The largest and smallest specimens were measured, 119 and a range of sizes between were chosen to represent a continuum. These are indicated in Table

1201 by those individuals with STD for only the mesosomal length measurements.

121 In addition to the sting measurements and mesosomal length measurements, we also

122 calculated a relative sting length based on a ratio of the sting length to the mesosomal length.

123 Toxicity, pain, and host preference

124 Measures of host preference, toxicity, and pain were derived from the literature (Brothers

125 \& Finnamore 1993; Schmidt 1986a; Schmidt 1986b; Schmidt 1990a; Schmidt 2004; Schmidt

126 2016; Schmidt et al. 1980; Schmidt et al. 1986; Starr 1985). Toxicity measures were only

127 available for a handful of species (Table 1). For some species (e.g., Polistes apaches), toxicity

128 measures were only available for closely related species within the same genus. In these cases we 129 averaged the published toxicity of other members of the genus to estimate an average toxicity for

130 these taxa. This averaging was only done at the genus level, so taxa without toxicity measures for other members of their genus were not included in the toxicity vs. sting length analyses.

While measuring pain from insect stings is undoubtedly a subjective endeavor, recently

the "Schmidt pain index" has received much attention as it attempts to compare the pain of various Hymenoptera stings using a scale of 1-4, 1 being low pain and 4 being high (Schmidt 2016). Unfortunately, in addition to the pain rankings being subjective, they are generally not assigned to specific species, but rather given as a range for a taxonomic group (e.g., velvet ants, small species get a pain ranking of $1-2$, but no species identifications are given for these "small species" (Schmidt 1990a)). To account for the lack of species-level measures of pain, we 
139 assigned each species we had a measure of sting length an estimated pain value based on the

140 actual value for related species (when known). In many wasp families no measures of pain have

141 been published, so for these instances we assigned potential pain values based on closely related

142 wasp families and personal experience. Linear regression was used to compare the relative sting

143 length to pain estimates.

144 Data Analysis. For the situations where there were multiple measurements for a given

145 species, these measurements were then averaged and standard deviations were calculated (Table 146 1).

To investigate what factors were associated with the sting length, we used an ANCOVA

148

149

150

151

152

153

154

155

156

157

158

159

160

161

with sting length as the response variable and mesosomal length, wasp type (velvet ant or other wasp), and the interaction between mesosomal length and wasp type as the predictor variables. Furthermore, we used linear regression to compare sting length to various other measures.

Toxicity measures (though only available for a subset of species) and pain estimates were individually compared to the relative sting length (sting length/mesosomal length) with relative sting length as the response variable, and either the pain estimates or the toxicity as the predictor variables. Sociality was also compared to relative sting length with relative sting length as the response variable and sociality (either social or solitary) predictor variables. Similarly sociality was compared to pain with pain being the response variable and sociality as the predictor variable. To determine if any trends existed in host choice, host data was compared to relative sting length with relative sting length as the response variable and host as the predictor variable. All analyses were computed using R (RDevelopment CORE TEAM 2008).

\section{Results}

Sting length 

and $13.5 \mathrm{~mm}$ with Dasymutilla occidentalis having the longest sting. The relative sting length varied, but was above 1 for all velvet ants with a species of Dasylabris from Russia having the longest relative length. Of the 39 non-velvet ant wasps measured, the actual sting length varied between $1 \mathrm{~mm}$ and $14.3 \mathrm{~mm}$ with the relative sting length being below 1 for all but a few species (Table 1). Pepsis sp. had the longest overall sting length $(14.33 \mathrm{~mm})$ though the relative sting length was 1 , indicating that the overall length was likely related to the large size of the wasp. Velvet ants had a much larger relative sting length compared to most other wasps, with an outlying wasp, Sapyga elegans, grouping with the velvet ants (Fig. 1b).

We found a significant positive relationship between mesosomal length and sting length $\left(F_{2,57}=111.2 ; R^{2}=0.796, P<0.0001\right)$ for both velvet ants and other aculeates (Fig. 1b).

Additionally we found that there was a significant difference between velvet ants and other aculeates $\left(F_{2,57}=111.2 ; R^{2}=0.796, P<0.0001\right)$. While both velvet ants and other aculeates show a positive relationship between mesosoma length and sting length, the significant interaction $\left(F_{3,56}=107.7 ; P<0.0001\right)$ between velvet ant and non-velvet ant datasets indicates that velvet ants sting length increases significantly more as the velvet ants body size increases compared to all other aculeates (Fig. 1b).

While we did find a significant positive relationship between overall sting length and pain $\left(F_{1,58}=18.75 ; R^{2}=0.2443, P<0.001\right)$, indicating that larger wasps generally have a more painful sting, we found no relationship between relative sting length (sting length compared to the mesosomal length) and pain $\left(F_{1,58}=0.2682 ; R^{2}=0.0046, P=0.6065\right)$. Furthermore, we found marginally significant evidence that toxicity was inversely related to sting length $\left(F_{1,7}=\right.$ 5.175; $\left.R^{2}=0.425, P=0.05707\right)$, indicating that aculeates with longer stings relative to their body 
185 size were less toxic than those with smaller stings relative to their body size (Fig. 2). Also, as has

186 previously been suggested (Schmidt et al. 1980; Schmidt et al. 1986), we found no significant

187 relationship between venom lethality and reported pain of the sting $\left(F_{1,7}=1.212 ; R^{2}=0.1476, P\right.$

$188=0.3073$ ). We did, however, find a weakly significant relationship between sociality and relative 189 sting length $\left(F_{1,58}=4.383 ; R^{2}=0.07026, P=0.04068\right)$, with social species having shorter stings

190 relative to their bodies than solitary species. We found no relationship, though, between

191 sociality and pain $\left(F_{1,58}=2.848 ; R^{2}=0.04681, P=0.09685\right)$.

192 We found that the species' ecology, the host/prey use in particular, was significantly 193 correlated to relative sting length $\left(F_{10,49}=19.49 ; R^{2}=0.7991, P<0.0001\right)$ with those taxa that use immature Hymenoptera as their host having significantly longer stings compared to their bodies than all other aculeates (Fig. 3). These include all of the velvet ants and the sapygid wasp 196 (a close relative of velvet ants (Branstetter et al. 2017)).

Discussion

Our results show that there is no link between relative sting length and pain. It should be mentioned that measuring the pain associated with stings is a subjective endeavor and these

201

202

203

204

205

206

207 measures should be viewed as soft assessments rather than hard metrics. Regardless, while one might assume the longer stings would inflict more pain, based on personal observation, when someone is stung by an aculeate wasp, the sting only shallowly penetrates the skin. This observation suggests that the sting length is not used to inject venom deeper into the victim, but likely has been selected for other purposes (discussed below). While sting length does not seem to be associated with pain, we did find an inverse relationship between relative sting length and toxicity (though only a limited number of taxa could be included in the analysis), with taxa 
208 having shorter relative stings being more toxic. This could be related to the way different taxa

209 use their stings. Most wasps use the sting to immobilize or kill their host (Schmidt 2016). There

210 is some necessity, therefore, for these wasps to evolve venoms that are toxic enough to

211 effectively immobilize their prey. Velvet ants, on the other hand, parasitize hosts (immature

212 hymenoptera) that are already immobile, and it has been suggested that their sting and associated

213 venom is primarily used for defense (Schmidt 2016). Highly toxic venom for defense might be

214 selected against, as it would be more beneficial for a velvet ant to inflict pain, but not mortally

215 wound a potential predator facilitating learned avoidance, which has been demonstrated in

216 feeding trials with various vertebrates (Gall et al. in press).

Our results clearly show that velvet ants have the longest stings out of the stinging wasps

218 in relation to their body size (Fig. 1a,b). For example, the velvet ant Dasymutilla occidentalis

219 had a sting nearly as long as the tarantula hawk (Pepsis sp.) that was twice its size (Table 1).

220 Some velvet ant species have been given the common name of "cow killer" (Schmidt 1990b),

221 which are theoretically named because anyone who was stung would claim it hurt bad enough to

222 "kill a cow" (Schmidt 2016). This ominous common name, however, is somewhat enigmatic

223 given that velvet ants have some of the least toxic venoms of any of the wasps (Schmidt 1986b;

224 Schmidt et al. 1980; Schmidt et al. 1986). While velvet ants have the longest sting (compared to

225 their body) out of any aculeate, their stings are, however, short compared to many parasitic

226 wasps. One of note being Euurobracon yokohamae, which has an ovipositor 7.7 times the length

227 of the body (Townes 1975).

228 It is not entirely clear why velvet ants have such long stings, yet the fact that sting length

229 is correlated to host type suggests something about their parasitic nature has driven the evolution 
230 of exceptionally long stings. Below, we will explore two potential hypotheses that might explain

231 the size of the velvet ant sting.

232 First, the long sting of velvet ants might help them immobilize their host in the tight

233 confines of the host nest cell. While little is known about the behavior of velvet ants when they

234 are in their host nest, it is clear that these wasps are parasitic primarily on immature bees and

235 sphecid wasps, generally parasitizing the prepupa or pupal stage of their host (Brothers \&

236 Finnamore 1993). Most velvet ants parasitize solitary, ground nesting species (Brothers \&

237 Finnamore 1993). To successfully parasitize a host, the parasite must find the host nest, open the

238 host nest cell (either underground or in a pre-existing cavity), and oviposit near the host prepupa

239 or pupa. From the few descriptions of velvet ant parasitism behaviors it appears that the adult

240 velvet ant opens the nest cell only enough to allow her head access, permitting her to probe the

241 nest cell with her antennae to determine if the host has finished consuming its provision

242 (indicating the nest cell is appropriate for oviposition) (Brothers 1972). Once an appropriate nest

243 cell is identified, the female velvet ant will turn around and insert the tip of the metasoma into

244 the opening in the wall of the nest cell and probe around with her sting (Brothers 1972). The

245 female velvet ant will sting the host only if it is in the pupal stage, but will simply oviposit if the

246 host is in the prepupal stage with the sting apparently serving to stop development of the host

247 (Brothers 1972; Janvier 1933). It is possible that the long sting of the velvet ants enhances their

248 ability to parasitize the host in the close confines of an underground nest cell.

249 This hypothesis, however, does not seem to be supported in other wasps. Scoliid wasps,

250 for example, also parasitize ground nesting hosts, specifically beetle larvae (Brothers \&

251 Finnamore 1993). While they undoubtedly also face similar challenges to the velvet ants in

252 finding a host and paralyzing it with a sting in the tight underground burrow of the beetle, yet 
253 scoliids do not have a long sting. This suggests that other factors, other than the tight confines of

254 the host underground nest might be playing a role in the selective advantage of the length of the

255 velvet ant's sting.

256 A second hypothesis regarding the length of velvet ant sting is that it evolved in response

257 to predation pressures. Velvet ants are among the most highly defended of all stinging wasps

258 (Manley 2000; Schmidt 2016; Schmidt \& Blum 1977). These defenses include aposematic

259 coloration, stridulation (auditory aposematism), pungent exudate secretions, a hard cuticle, and a

260 painful sting (Manley 2000; Schmidt 2016; Wilson et al. 2012). Not only do velvet ants have the

261 longest stings (as our results clearly show), they also have one of the most flexible and

262 maneuverable apical metasomal segments enabling them to reach their sting to nearly every part

263 of their body (Schmidt 2016). Because velvet ant's hosts are largely immobile, they are thought

264 to only rarely sting their prey (Schmidt 2016), instead it has been suggested their sting is

265 primarily used to defend against predators (Schmidt \& Blum 1977). In fact, the length of the

266 sting, combined with the hard cuticle of the velvet ants makes them nearly indestructible (Vitt \&

267 Cooper 1988).

268 Several of the more unique aspects of the velvet ant sting and venom make them highly

269 effective against predators. First, as is mentioned above, the length and agility of the sting,

270 combined with their extraordinarily hard cuticle, aposematic coloration, and stridulation enables

271 velvet ants to quickly and effectively train predators to avoid them. Gall et al. (in press), for

272 example, found that when a lizard (in this study the lizard was Aspidoscelis tigris) attacks a

273 velvet ant, it is unable to crush it because of the hard cuticle, as the lizard attempts to manipulate

274 the velvet ant in its mouth, the velvet ant is quickly able to sting the lizard. Once released, the

275 aposematic coloration of the velvet ant apparently facilitates rapid learning in the lizard. In many 
276 instances after experiencing the sting of a velvet ant (and the other defenses) a lizard will not

277 attempt to attack another velvet ant, even with over a year between exposures to these wasps

278 (Gall et al. in press). The second aspect of velvet ant stings and venom chemistry that make them

279 highly effective predatory deterrents is the mildly toxic, but highly painful sting. This enables

280 velvet ants to train predators with a painful sting, but the mild toxin does no lasting damage.

281 The highly effective defenses of velvet ants, of which the long sting plays a key role,

282 have enabled velvet ants to diversify around the world. Furthermore, these defenses have been

283 influential in the evolution of the world's largest known Müllerian mimicry complex among

284 diurnal velvet ants (Wilson et al. 2015; Wilson et al. 2018; Wilson et al. 2012).

\section{Conclusions}

Our study of the sting length of various bees, wasps, and ants finds that velvet ants have

287

288

289

290

291

292

293

294

295

296

297

298

the longest sting compared to their body size out of any aculeate. While there was no link between relative sting length and the pain associated with the sting, we did find an inverse relationship between relative sting length and toxicity, with taxa that have shorter relative stings being more toxic. While we found a significant relationship between host use and relative sting length, we suggest that the long sting length of the velvet ants may also be related to their suite of defenses to avoid predation.

\section{Acknowledgements}

We thank Alex Kelley, Katie Weglarz, Nicole Boehme, Sarah Clark, Jake Jones, Andrew Ermer, Erik Pilgrim, David Tanner, Barry Webster, Edmund Williams, and Kevin Williams for help in collecting specimens.

\section{References}


299

300

301

302

303

304

305

306

307

308

309

310

311

312

313

314

315

316

317

318

319

320

Blum M. 2012. Chemical defenses of arthropods: Elsevier.

Bosch J, and Vicens N. 2002. Body size as an estimator of production costs in a solitary bee. Ecological Entomology 27:129-137. DOI: 10.1046/j.1365-2311.2002.00406.x

Branstetter MG, Danforth BN, Pitts JP, Faircloth BC, Ward PS, Buffington ML, Gates MW, Kula RR, and Brady SG. 2017. Phylogenomic insights into the evolution of stinging wasps and the origins of ants and bees. Current Biology 27:1019-1025. doi: 10.1016/j.cub.2017.03.027.

Brothers DJ. 1972. Biology and immature stages of Pseudomethoca f. frigida, with notes on other species (Hymenoptera: Mutillidae). 50:1-38.

Brothers DJ, and Finnamore AT. 1993. Superfamily Vespoidea.

Fitzgerald KT, and Flood AA. 2006. Hymenoptera stings. Topics in Companion Animal Medicine 21:194-204. DOI: https://doi.org/10.1053/j.ctsap.2006.10.002

Gall, BG, Spivey KL, Chapman TL, Delph RJ, Brodie ED, and Wilson JS. in press. The Indestructible Insect: Velvet Ants from Across the United States Avoid Predation by Representatives from all Major Tetrapod Clades. Ecology and Evolution.

Greenleaf SS, Williams NM, Winfree R, and Kremen C. 2007. Bee foraging ranges and their relationship to body size. Oecologia 153:589-596. doi: 10.1007/s00442-007-0752-9

Haggard CM, and Gamboa GJ. 1980. Seasonal variation in body size and reproductive condition of a paper wasp, Polistes metricus (Hymenoptera: Vespidae). The Canadian Entomologist 112:239-248. doi: https://doi.org/10.4039/Ent112239-3

Janvier H. 1933. Étude biologique de quelques hyménopteres du Chilli. Annates du Science Naturelle Zoologique 16:209-356. 
321 Manley DG. 2000. Defense adaptations in velvet ants (Hymenoptera: Mutillidae) and their

322

323

324

325

326

327

328

329

330

331

332

333

334

335

336

337

338

339

340

341

342

possible selective pressures. Hymenoptera: evolution, biodiversity and biological control, Fourth international Hymenoptera Conference, Canberra, Australia Melbourne: CSIRO Publishing. p 285-289.

Piek T. 1986. Historical Inroduction. In: Piek T, ed. Venoms of the Hymenoptera: biochemical, pharmacological and behavioural aspects: Academic Press.

Rasband WS, ImageJ U, and Health NIo. 2011. Bethesda, Maryland, USA, 1997-2014. URL: http://imagej nih gov/ij/(16 4 2013).

RDevelopment CORE TEAM R. 2008. R: A language and environment for statistical computing. $\mathrm{R}$ foundation for statistical computing Vienna, Austria.

Roffet-Salque, M, Regert, M,...Zoughlami, J. 2015. Widespread exploitation of the honeybee by early Neolithic farmers. Nature. 527:226-230. doi: http://dx.doi.org/10.1038/nature15757

Schmidt JO. 1986a. Allergy to Hymenoptera venoms. Venoms of the Hymenoptera: Academic Press London, 509.

Schmidt JO. 1986b. Chemistry, pharmacology and chemical ecology of ant venoms. In: Piek T, ed. Venoms of the Hymenoptera. Orlando, Florida: Academic Press, 425-508.

Schmidt JO. 1990a. Hymenopteran venoms: striving toward the ultimate defense against vertebrates. In: DL E, and JO S, eds. Insect defenses: adaptive mechanisms and strategies of prey and predators. New York: State University of New York., 387-419.

Schmidt JO. 1990b. Insect defenses: adaptive mechanisms and strategies of prey and predators: SUNY Press. 
343 Schmidt JO. 2004. Venom and the good life in tarantula hawks (Hymenoptera: Pompilidae): how to eat, not be eaten, and live long. Journal of the Kansas Entomological Society 77:402413. doi: https://doi.org/10.2317/E-39.1

346 Schmidt JO. 2016. The sting of the wild: JHU Press.

347 Schmidt JO, and Blum MS. 1977. Adaptations and responses of Dasymutilla occidentalis (Hymenoptera: Mutillidae) to predators. Entomologia experimentalis et applicata 21:99111. DOI: $10.1111 / \mathrm{j} .1570-7458.1977 . t b 02663 . x$

Schmidt JO, Blum MS, and Overal WL. 1980. Comparative lethality of venoms from stinging Hymenoptera. Toxicon 18:469-474. doi: https://doi.org/10.1016/0041-0101(80)90054-9 Entomological Science 20:225-232.

Townes H. 1975. The parasitic Hymenoptera with the longest ovipositors, with descriptions of stinging Hymenoptera. Toxicon 24:907-921. doi: https://doi.org/10.1016/0041$\underline{0101(86) 90091-7}$

Starr CK. 1985. A simple pain scale for field comparison of hymenopteran stings. Journal of

Vitt LJ, and Cooper WE. 1988. Feeding responses of skinks (Eumeces laticeps) to velvet ants (Dasymutilla occidentalis). Journal of Herpetology 22:485-488. complexes. Current Biology 25:R704-R706. DOI: https://doi.org/10.1016/j.cub.2015.06.053 
365 Wilson JS, Pan AD, Limb ES, and Williams KA. 2018. Comparison of African and North American velvet ant mimicry complexes: Another example of Africa as the 'odd man out'. PloS one 13:e0189482. doi: https://doi.org/10.1371/journal.pone.0189482

368 Wilson JS, Williams KA, Forister ML, Von Dohlen CD, and Pitts JP. 2012. Repeated evolution 369 in overlapping mimicry rings among North American velvet ants. Nature Communications 3:1272. 
373

374

375

376

377

378

379

380

381

382

383

384

385

386

387

388

389

390

391

\section{Figure Legends}

Figure 1. Sting length vs. mesosomal length among aculeates. (a) Dasymutilla calorata with her sting extended showing its length. (b) Graph of mesosomal length vs. sting length. Velvet ants are indicated in black and other aculeates in grey. Regression lines are indicated. Examples of various velvet ants and other aculeates are also pictured.

Figure 2. Graph of relative sting length versus toxicity. Relative sting length is negatively correlated to toxicity. Relative sting length is a ratio of the sting length/mesosomal length and toxicity is measured in $\mathrm{mg} / \mathrm{kg}$ with lower numbers being more toxic. Velvet ants are marked with black and other aculeates are marked with grey.

Figure 3. Relative sting length compared to host preferences. Relative sting length is significantly correlated to host use in those wasps that parasitize immature Hymenoptera, but not in all other aculeates. (a) Boxplot showing relative sting length vs. host use. (b) Scatter plot of sting length vs. mesosomal length (see Fig. 1) with taxa colored based on host preferences. 


\section{Table $\mathbf{1}$ (on next page)}

Aculeate taxa included in analyses.

Sting and mesosomal lengths are given in $\mathrm{mm}$ and relative sting length is a ratio of sting length/mesosomal length. Sociality, host data, toxicity, and pain are derived from the literature (Brothers \& Finnamore 1993; Schmidt 1986a; Schmidt 1986b; Schmidt 1990a; Schmidt 2004; Schmidt 2016; Schmidt et al. 1980; Schmidt et al. 1986; Starr 1985). Toxicity data were not available for all taxa, but where possible, toxicity data for closely related species (within the same genus) was averaged for the genus and included in the table (e.g., Polistes). Similarly, pain data were not available for all taxa, but estimated pain values were included based on reported pain values, personal observation, or known pain indices from related taxa. 
1 Table 1. Aculeate taxa included in analyses. Sting and mesosomal lengths are given in $\mathrm{mm}$ and relative sting length is a ratio of sting

2 length/mesosomal length. Sociality, host data, toxicity, and pain are derived from the literature (Brothers \& Finnamore 1993; Schmidt

3 1986a; Schmidt 1986b; Schmidt 1990a; Schmidt 2004; Schmidt 2016; Schmidt et al. 1980; Schmidt et al. 1986; Starr 1985). Toxicity

4 data were not available for all taxa, but where possible, toxicity data for closely related species (within the same genus) was averaged

5 for the genus and included in the table (e.g., Polistes). Similarly, pain data were not available for all taxa, but estimated pain values

6 were included based on reported pain values, personal observation, or known pain indices from related taxa.

\begin{tabular}{|c|c|c|c|c|c|c|c|c|c|c|}
\hline Family & Species & Sting & STD & Mesosoma & STD & $\begin{array}{c}\text { Relative } \\
\text { sting } \\
\text { length }\end{array}$ & Sociality & Prey/host & $\begin{array}{l}\text { Toxicity } \\
\text { (LD50 } \\
\text { mg/kg) }\end{array}$ & Pain \\
\hline Rhopalosomatidae & $\begin{array}{l}\text { Rhopalosomatidae } \\
\text { nearcticum }\end{array}$ & 2.15 & & 3.29 & & 0.65 & solitary & Grylloptera & & 1 \\
\hline \multirow{2}{*}{ Vespidae } & Vespa crabro & 5.39 & 0.28 & 9 & 0.57 & 0.6 & social & Predator & 2.9 & 2 \\
\hline & Polistes apachus & 3.81 & 0.52 & 6.44 & 0.45 & 0.59 & social & Predator & 3.7 & 2.5 \\
\hline \multirow{2}{*}{ Tiphiidae } & Tiphia sp. 1 & 3.66 & & 4.71 & & 0.78 & solitary & Coleoptera & & 1 \\
\hline & Tiphia sp. 2 & 2.7 & 0.45 & 5.54 & 0.69 & 0.49 & solitary & Coleoptera & & 1 \\
\hline \multirow{4}{*}{ Chyphotidae } & Typhoctes peculiaris & 3.06 & & 3.07 & & 1 & solitary & Unknown & & 1 \\
\hline & Chyphotes mandibularis & 2.28 & & 3.38 & & 0.67 & solitary & Unknown & & 1 \\
\hline & Chyphotes albipes & 1.26 & 0.24 & 1.67 & 0.31 & 0.75 & solitary & Unknown & & 1 \\
\hline & Chyphotes belfragei & 1.83 & 0.3 & 2.83 & 0.47 & 0.65 & solitary & Unknown & & 1 \\
\hline \multirow{4}{*}{ Thynnidae } & Methoca stugia & 2.89 & & 2.18 & & 1.32 & solitary & Coleoptera & & 1 \\
\hline & Diamma bicolor & 3.87 & & 8.19 & & 0.47 & solitary & Coleoptera & & 3 \\
\hline & Anthobosca sp. & 2.1 & & 2.69 & & 0.78 & solitary & Coleoptera & & 1 \\
\hline & Myzinum sp. & 4.73 & & 5.43 & & 0.87 & solitary & Coleoptera & & 1 \\
\hline Pompilidae & $\begin{array}{l}\text { Anoplius (Notiochares) } \\
\text { lepidus }\end{array}$ & 5.49 & & 9.1 & & 0.6 & solitary & Spiders & & 2.5 \\
\hline
\end{tabular}




\begin{tabular}{|c|c|c|c|c|c|c|c|c|c|c|}
\hline & $\begin{array}{l}\text { Anoplius (Pompilinus) } \\
\text { insolens }\end{array}$ & 3.39 & & 4.72 & & 0.72 & solitary & Spiders & & 2.5 \\
\hline & Aporus luxus & 4.37 & & 5.41 & & 0.81 & solitary & Spiders & & 2.5 \\
\hline & Ageniella blaisdellii & 2.69 & & 3.84 & & 0.7 & solitary & Spiders & & 2.5 \\
\hline & Entypus unifasciatus & 4.74 & & 8.43 & & 0.56 & solitary & Spiders & & 2.5 \\
\hline & Evagetes sp. & 2.07 & & 3 & & 0.69 & solitary & Spiders & & 2.5 \\
\hline & Pepsis sp. & 14.33 & & 14.35 & & 1 & solitary & Spiders & 65 & 4 \\
\hline & Tachypompilus sp. & 4.66 & & 9.08 & & 0.51 & solitary & Spiders & & 2.5 \\
\hline & Sericopompilus sp. & 4.31 & & 5.24 & & 0.82 & solitary & Spiders & & 2.5 \\
\hline & Arachnospila arctus & 3.54 & & 4.82 & & 0.73 & solitary & Spiders & & 2.5 \\
\hline & $\begin{array}{l}\text { Anoplius } \\
\text { (Arachnophroctonus) } \\
\text { chiapanas }\end{array}$ & 3.96 & & 5.14 & & 0.77 & solitary & Spiders & & 2.5 \\
\hline Sapygidae & Sapyga elegans & 4.89 & 1.64 & 3.61 & 0.39 & 1.35 & solitary & $\begin{array}{c}\text { Immature } \\
\text { Hymenoptera }\end{array}$ & & 1 \\
\hline Myrmosidae & Myrmosa unicolor & 2.41 & & 2.21 & & 1.09 & solitary & Coleoptera & & 1 \\
\hline \multirow{9}{*}{ Mutillidae } & Atillum jucundum & 8.1 & & 5.24 & & 1.55 & solitary & $\begin{array}{c}\text { Immature } \\
\text { Hymenoptera }\end{array}$ & & 2 \\
\hline & $\begin{array}{l}\text { Cephalomutilla } \\
\text { haematodes }\end{array}$ & 4.85 & & 2.98 & & 1.63 & solitary & $\begin{array}{c}\text { Immature } \\
\text { Hymenoptera }\end{array}$ & & 2 \\
\hline & Dasylabris sp. & 7.84 & & 3.38 & & 2.32 & solitary & $\begin{array}{c}\text { Immature } \\
\text { Hymenoptera }\end{array}$ & & 2 \\
\hline & Dasymutilla gloriosa & 9.11 & & 4.68 & & 1.94 & solitary & $\begin{array}{c}\text { Immature } \\
\text { Hymenoptera }\end{array}$ & & 2 \\
\hline & Dasymutilla nigripes & 5.96 & & 3.14 & & 1.9 & solitary & $\begin{array}{c}\text { Immature } \\
\text { Hymenoptera }\end{array}$ & & 2 \\
\hline & Dasymutilla occidentalis & 13.52 & 0.98 & 7.42 & 0.54 & 1.82 & solitary & $\begin{array}{c}\text { Immature } \\
\text { Hymenoptera }\end{array}$ & 71 & 3 \\
\hline & Ephuta bellus & 3.34 & & 1.92 & & 1.74 & solitary & $\begin{array}{c}\text { Immature } \\
\text { Hymenoptera }\end{array}$ & & 1 \\
\hline & Hoplomutilla phoreys & 9.31 & & 6.86 & & 1.36 & solitary & $\begin{array}{c}\text { Immature } \\
\text { Hymenoptera }\end{array}$ & & 2 \\
\hline & Hoplomutilla xanthocerata & 11.91 & & 8.08 & & 1.47 & solitary & $\begin{array}{c}\text { Immature } \\
\text { Hymenoptera }\end{array}$ & & 2 \\
\hline
\end{tabular}




\begin{tabular}{|c|c|c|c|c|c|c|c|c|c|c|}
\hline & Mutillina sp. & 6.69 & & 5.03 & & 1.33 & solitary & $\begin{array}{c}\text { Immature } \\
\text { Hymenoptera } \\
\end{array}$ & & 1.5 \\
\hline & Myrmilla erythrocephala & 4.01 & & 3.44 & & 1.16 & solitary & $\begin{array}{c}\text { Immature } \\
\text { Hymenoptera }\end{array}$ & & 1.5 \\
\hline & Pertyella haracioi & 4.83 & & 3.35 & & 1.44 & solitary & $\begin{array}{c}\text { Immature } \\
\text { Hymenoptera }\end{array}$ & & 1.5 \\
\hline & Pristomutilla sp. & 4.1 & & 3.08 & & 1.33 & solitary & $\begin{array}{c}\text { Immature } \\
\text { Hymenoptera } \\
\end{array}$ & & 1.5 \\
\hline & Pseudomethoca sanbornii & 5.98 & & 3.49 & & 1.71 & solitary & $\begin{array}{c}\text { Immature } \\
\text { Hymenoptera }\end{array}$ & & 1.5 \\
\hline & Pseudophotopsis komarovii & 6.85 & & 4.94 & & 1.39 & solitary & $\begin{array}{c}\text { Immature } \\
\text { Hymenoptera }\end{array}$ & & 1.5 \\
\hline & Sigilla dorsata & 4.46 & & 3.14 & & 1.42 & solitary & $\begin{array}{c}\text { Immature } \\
\text { Hymenoptera } \\
\end{array}$ & & 1.5 \\
\hline & Smicromyrme viduata & 9.25 & & 4.51 & & 2.05 & solitary & $\begin{array}{c}\text { Immature } \\
\text { Hymenoptera }\end{array}$ & & 1.5 \\
\hline & $\begin{array}{l}\text { Sphaeropthalma } \\
\text { pensylvanica }\end{array}$ & 7.55 & & 4.13 & & 1.83 & solitary & $\begin{array}{c}\text { Immature } \\
\text { Hymenoptera }\end{array}$ & & 2 \\
\hline & Stenomutilla argentata & 5.77 & & 2.85 & & 2.02 & solitary & $\begin{array}{c}\text { Immature } \\
\text { Hymenoptera }\end{array}$ & & 2 \\
\hline & Timulla grotei & 5.69 & 0.3 & 3.54 & 0.21 & 1.61 & solitary & $\begin{array}{c}\text { Immature } \\
\text { Hymenoptera } \\
\end{array}$ & & 2 \\
\hline & $\begin{array}{l}\text { Tramautomutilla sp. } \\
\text { Paraguay }\end{array}$ & 10.44 & & 6.27 & & 1.67 & solitary & $\begin{array}{c}\text { Immature } \\
\text { Hymenoptera } \\
\end{array}$ & & 3 \\
\hline Bradynobaenidae & Apterogyna sp. & 2.36 & & 1.93 & & 1.22 & solitary & Unknown & & 1 \\
\hline Diraymonatintale & Bradynobaenus sp. & 2.02 & & 1.93 & & 1.05 & solitary & Unknown & & 1 \\
\hline Scolidae & Scoliia dubia dubia & 5.06 & & 8.9 & & 0.57 & solitary & Coleoptera & & 1 \\
\hline Stontad & Camposomerus tolteca & 4.59 & 0.4 & 7.2 & 0.6 & 0.64 & solitary & Coleoptera & 63 & 1 \\
\hline Formicidge & Paraponera clavata & 4.89 & 0.14 & 6.32 & 0.6 & 0.77 & social & Predator & 6 & 4 \\
\hline Foniticiate & Solenopsis invicta & 0.77 & 0.12 & 1.31 & 0.33 & 0.59 & social & Predator & & 1 \\
\hline & Bicyrtes caprioptera & 4.23 & & 5.22 & & 0.81 & solitary & Hemiptera & & 1 \\
\hline Crabronidae & Sphecius speciosus & 9.38 & & 11.49 & & 0.82 & solitary & Hemiptera & 46 & 1.5 \\
\hline travionituate & Oxybelus argentiopilosus & 1.09 & & 1.66 & & 0.66 & solitary & Diptera & & 1 \\
\hline & Astata bakeri & 1.74 & & 3.73 & & 0.47 & solitary & Hempitera & & 1 \\
\hline
\end{tabular}




\begin{tabular}{|c|c|c|c|c|c|c|c|c|c|c|}
\hline & Bembix amoena & 4.46 & 0.24 & 6.98 & 0.39 & 0.64 & solitary & Diptera & & 1 \\
\hline \multirow{2}{*}{ Apidae } & Apis mellifera & 2.99 & 0.13 & 4.69 & 0.39 & 0.64 & social & Herbivore & 2.8 & 2 \\
\hline & Xvlocopa virginica & 5.02 & 0.44 & 7.81 & 0.64 & 0.64 & solitary & Herbivore & 22 & 1 \\
\hline
\end{tabular}




\section{Figure 1}

Sting length vs. mesosomal length among aculeates.

(a) Dasymutilla calorata with her sting extended showing its length. (b) Graph of mesosomal length vs. sting length. Velvet ants are indicated in black and other aculeates in grey. Regression lines are indicated. Examples of various velvet ants and other aculeates are also pictured. Photo credit: Joseph S. Wilson. 
(a)

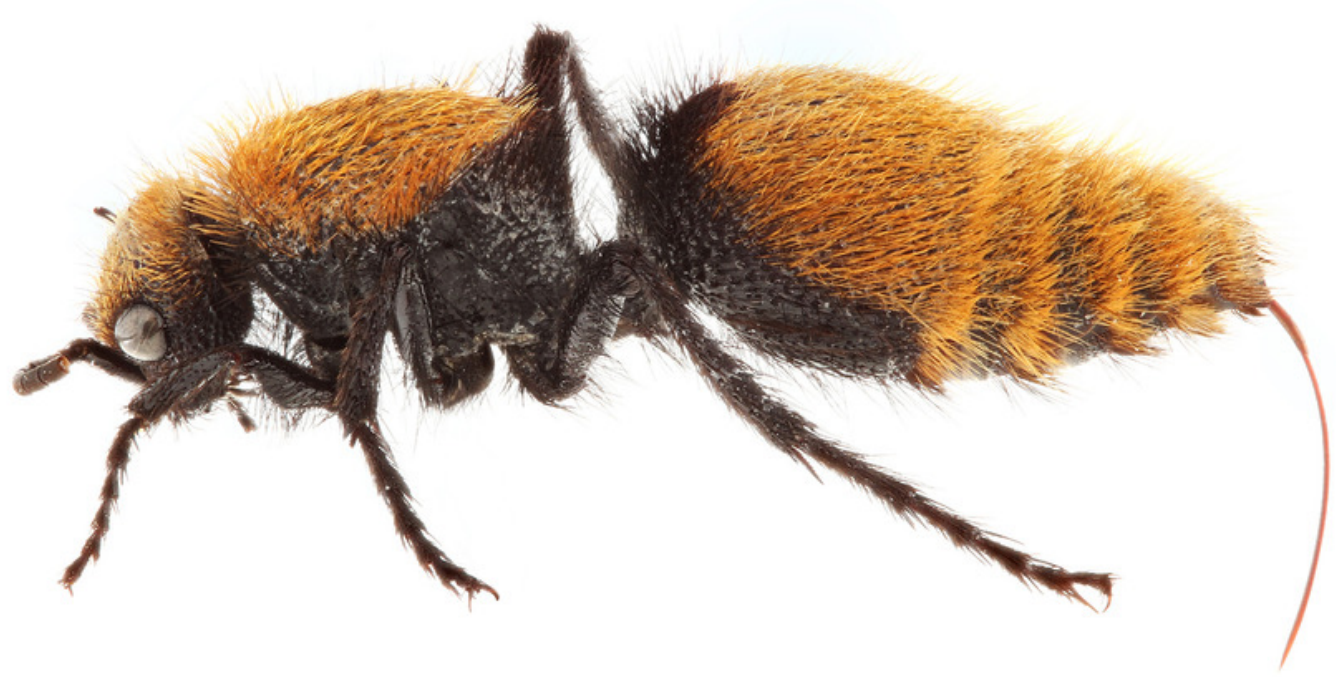

(b)

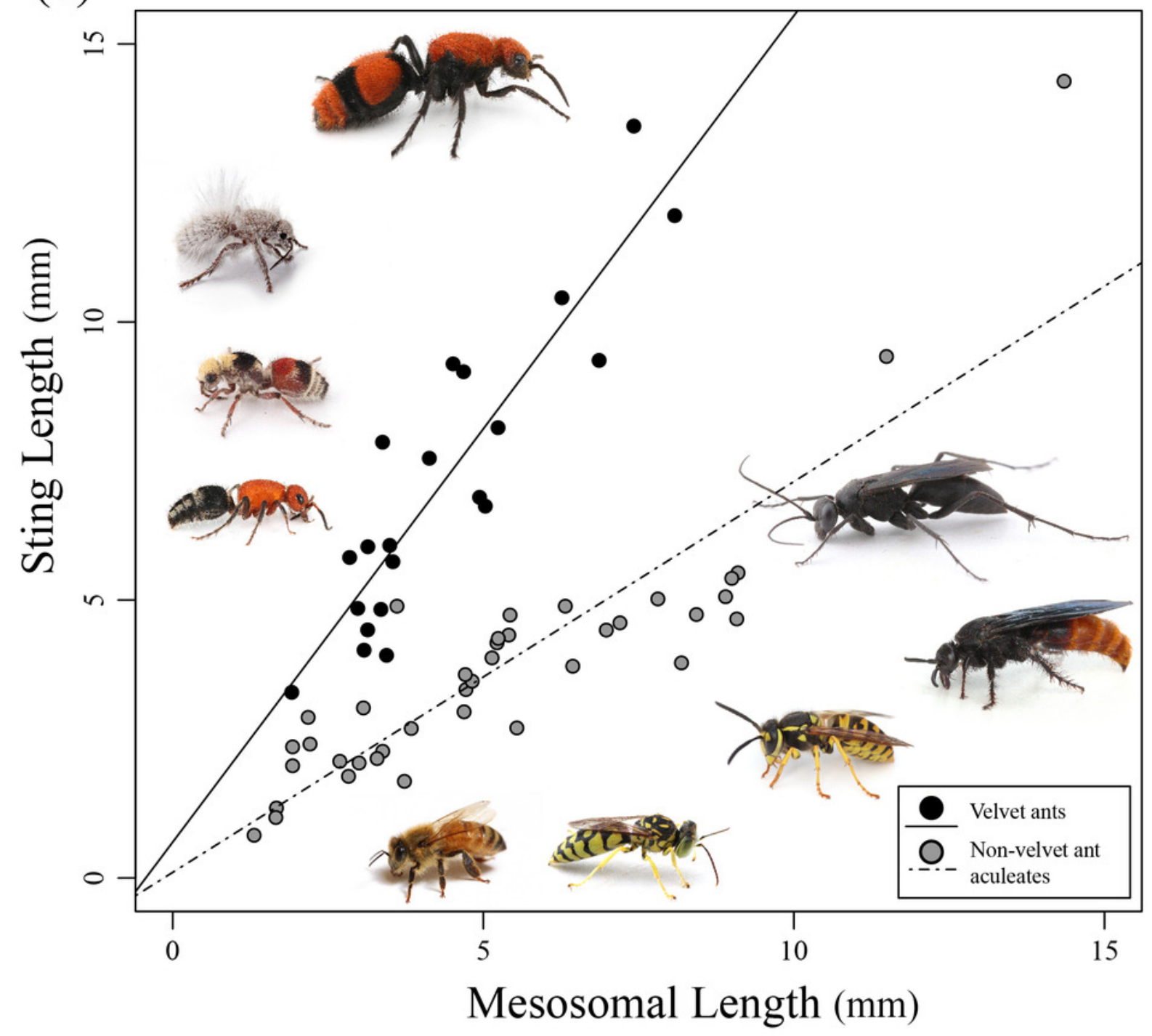


Figure 2

Graph of relative sting length versus toxicity.

Relative sting length is negatively correlated to toxicity. Relative sting length is a ratio of the sting length/mesosomal length and toxicity is measured in $\mathrm{mg} / \mathrm{kg}$ with lower numbers being more toxic. Velvet ants are marked with black and other aculeates are marked with grey.

*Note: Auto Gamma Correction was used for the image. This only affects the reviewing manuscript. See original source image if needed for review.

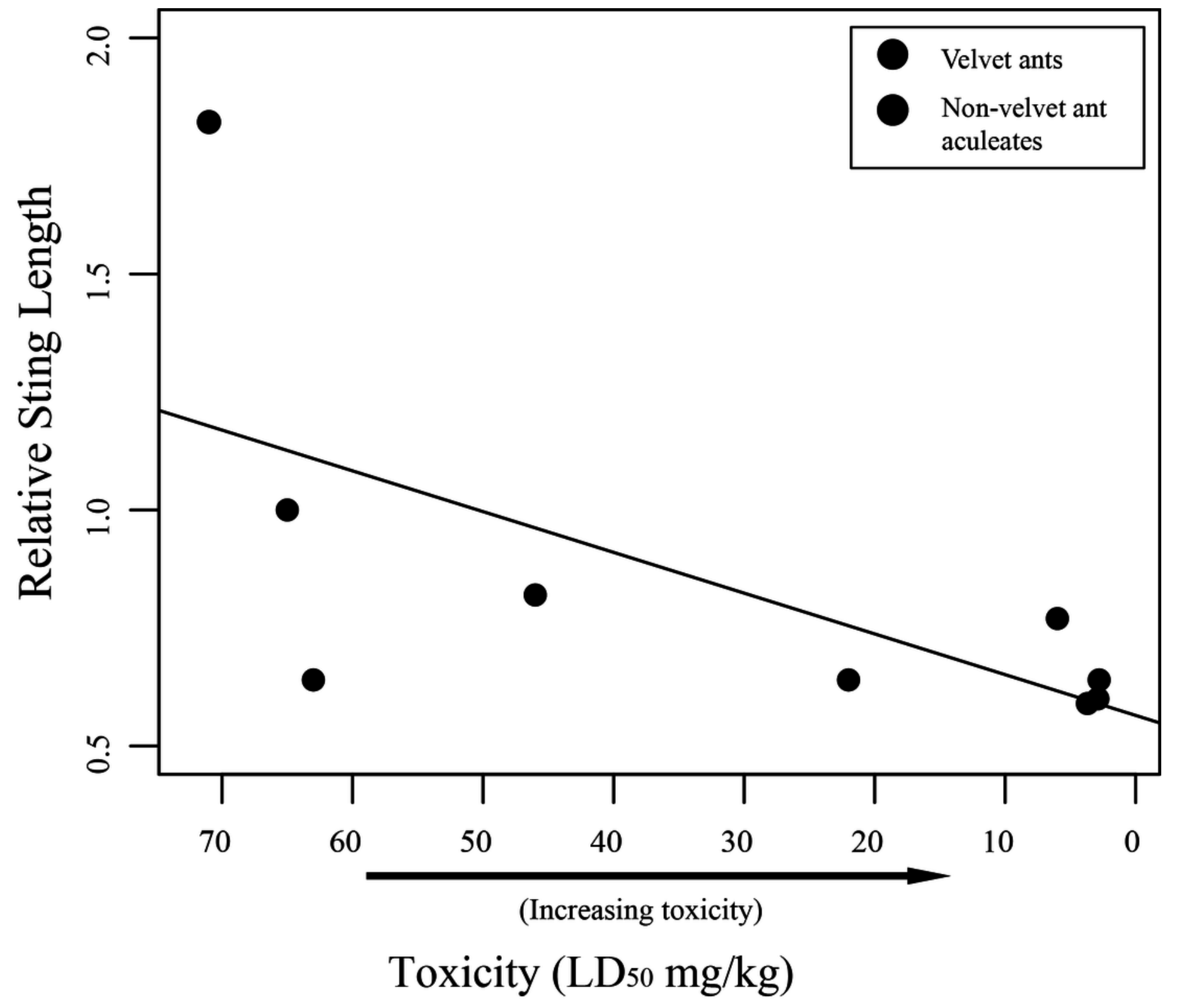




\section{Figure 3}

Relative sting length compared to host preferences.

Relative sting length is significantly correlated to host use in those wasps that parasitize immature Hymenoptera, but not in all other aculeates. (a) Boxplot showing relative sting length vs. host use. (b) Scatter plot of sting length vs. mesosomal length (see Fig. 1) with taxa colored based on host preferences. 


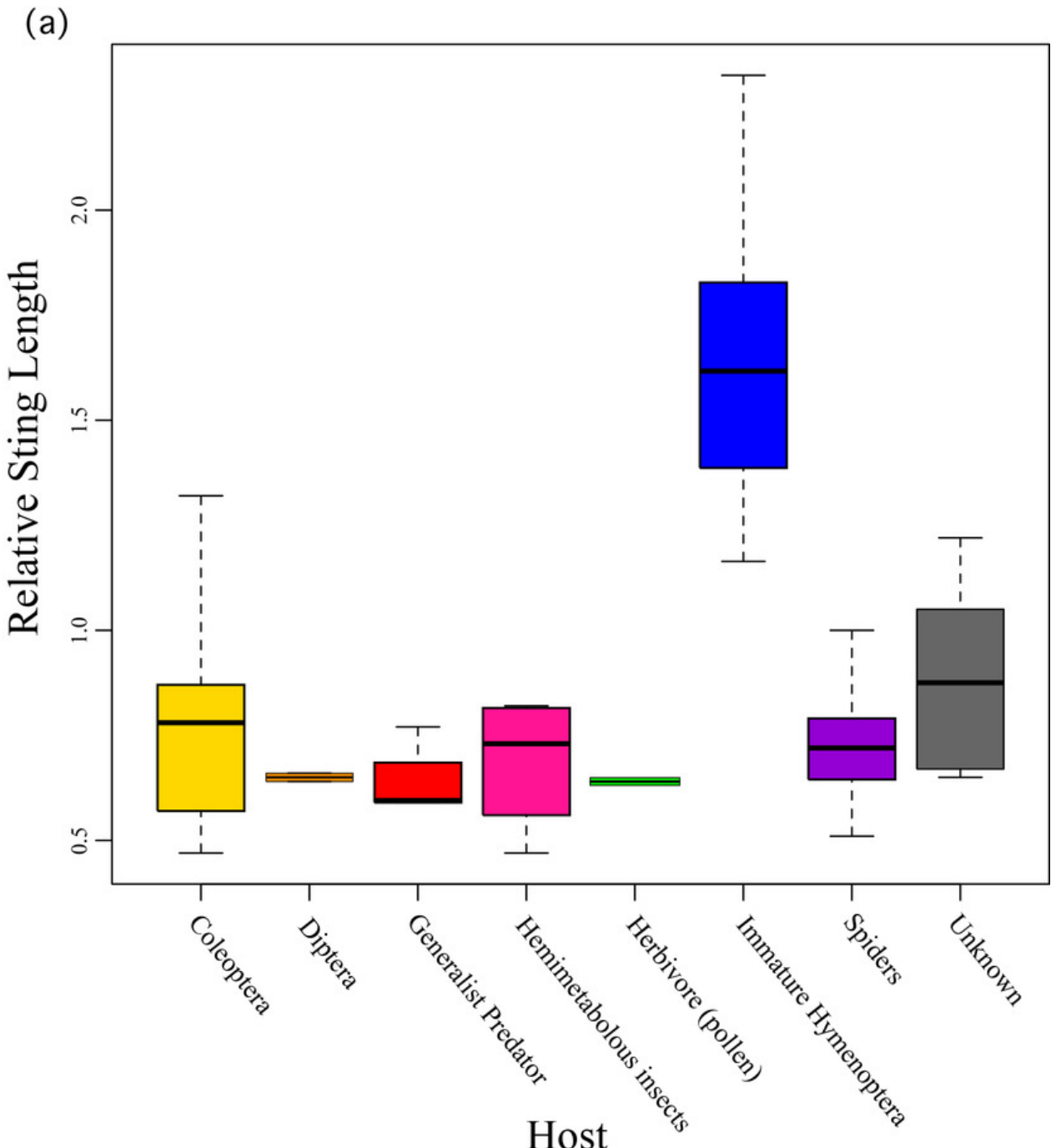

(b)

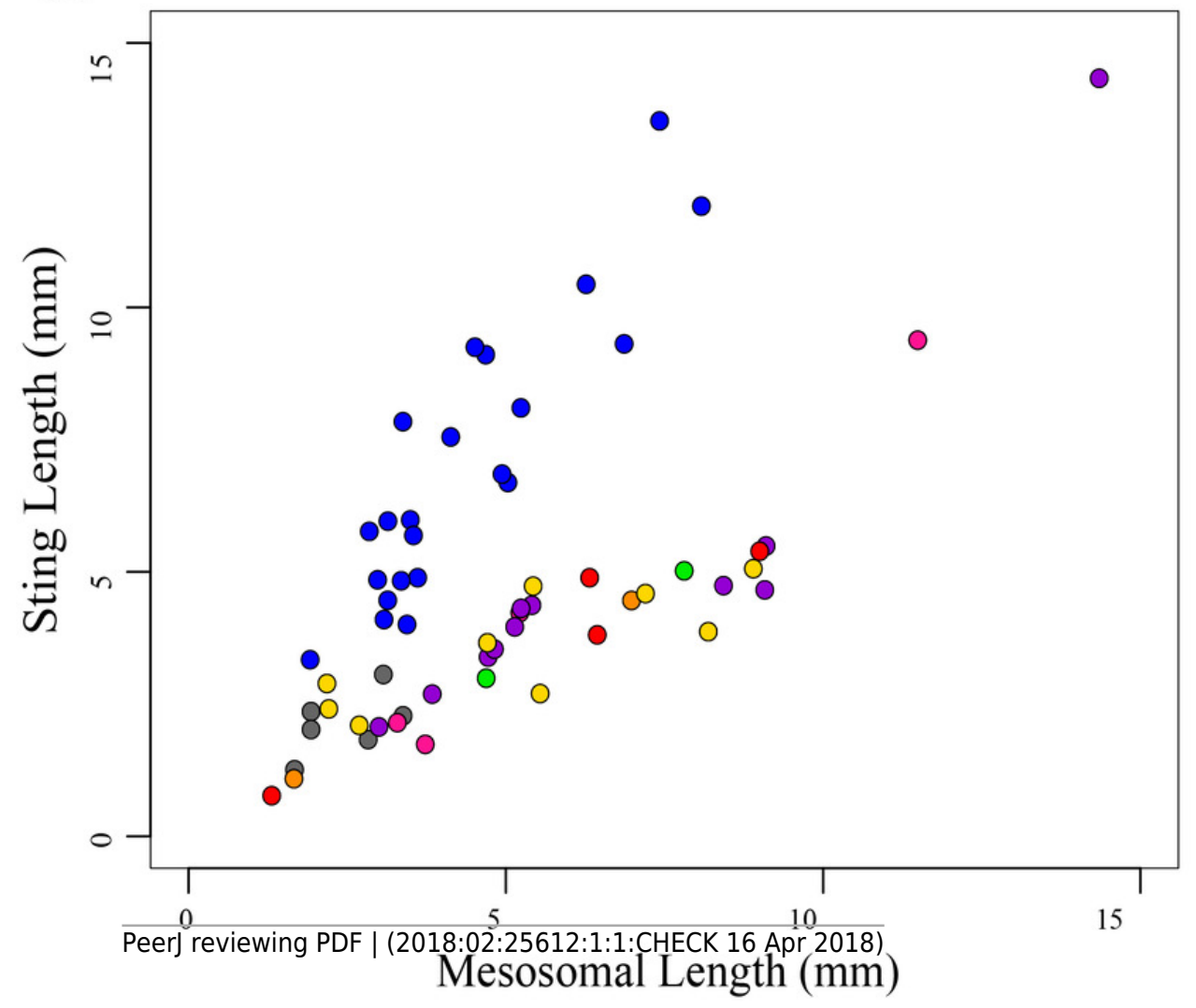

